\title{
SUSTAINABLE MALARIA CONTROL POLICY AND INFANT MORTALITY IN AN AGRARIAN ECONOMY: EVIDENCE FROM NIGERIA
}

\author{
D.A. Babalola ${ }^{1 *}$, P.E. Omeonu ${ }^{2}$, B.O. Osuntade ${ }^{1}$, A.E. Julius ${ }^{3}$ and I. Kalu ${ }^{4}$ \\ ${ }^{1}$ Department of Agriculture and Industrial Technology, Babcock University, Ogun state \\ Nigeria. \\ ${ }^{2}$ Faculty of Basic Medical Sciences, Clifford University, Ihie, Nigeria \\ ${ }^{3}$ Department of Public and Allied Health, Babcock University, Ogun state Nigeria \\ ${ }^{4}$ Faculty of Humanities, General Educ. Studies Unit, Clifford University, Ihie, Nigeria \\ *Corresponding Author Email: babalolada@ babcock.edu.ng
}

Cite this article:

Babalola D.A., Omeonu P.E., Osuntade B.O., Julius A.E.,

Kalu I. (2021), Sustainable

Malaria Control Policy and

Infant Mortality in an

Agrarian Economy: Evidence from Nigeria. African Journal of Economics and Sustainable Development 4(3), 85-97. DOI: 10.52589/AJESD3UH6DXWE.

\section{Manuscript History}

Received: 13 Sept 2021

Accepted: 30 Sept 2021

Published: 8 Oct 2021

Copyright $(9) 2020$ The Author(s). This is an Open Access article distributed under the terms of Creative Commons AttributionNonCommercial-NoDerivatives 4.0 International (CC BY-NC-ND 4.0 ), which permits anyone to share, use, reproduce and redistribute in any medium, provided the original author and source are credited.
ABSTRACT: Sustainable implementation of policy to control malaria is sine qua non to reduce the infant mortality rate especially in agrarian economies like Nigeria where malaria is common. This study examined the relationship between infant mortality rate and government expenditure on malaria (GEM) (proxy for health policy as explanatory variable), per capita income, infrastructure development index (IDI), government expenditure on education and health (as control variables) using data from 1990 to 2019 obtained from the World Bank and African Development Bank database. The unit root test conducted showed that all the variables were not stationary at first difference. The co-integration test established a long run equilibrium relationship between the variables which suggested the use of the Error Correction Model. The analysis of the estimated coefficients in the model showed that IDI and GEM significantly reduce infant mortality rate at $P<0.05$. Improvement in government funding to control malaria and efforts to develop infrastructure especially in the rural agrarian communities is recommended.

KEYWORDS: Malaria, Health Policy, Mortality Rate, Infrastructure Development Index, Error Correction Model, Nigeria 


\section{INTRODUCTION}

Good health which is the absence of diseases is generally rated by all as pertinent. Factors that diminish good health will increase mortality rate especially among infants who are the most vulnerable (Cutler, Deaton \& Lleras-Muney, 2006). Statistics have consistently shown that one in three deaths in the world is the death of an under five year old, and most of these deaths occur in the developing world (Grant, 1988; Ahonsi, 1992; Adesoye \& Babalola, 2017). Despite the decline in overall developing world mortality levels since 1950, the infant mortality rate is still on the increase in Sub-Saharan Africa (World Bank, 2015). Nigeria, since the 1980s, has been rated to have the 30th highest early mortality rate in the world (Abu, Madu \& Ajaero, 2015). Currently, Nigeria, with an infant mortality rate of 67 deaths per 1000 new births, has the third highest (following Mali and Sierra Leone) infant mortality rate in the West African region (African Development Bank [AfDB], 2018; World Bank, 2018). Up till present, nearly 50 percent of all deaths still occur among children below five years of age (WHO, 2020; Ransome-Kuti, 1986; Babalola, Olarewaju, Omeonu, Adefelu and Okeowo, 2013; Adeokun, 1985).

Among the major diseases responsible for infant mortality in Africa is malaria which kills a child every 2 minutes (RBM Partnership, 2020). In fact malaria, together with HIV and tuberculosis are rated as the greatest threats to life expectancy, infant mortality and economic development in Sub-Saharan Africa (Alaba \& Alaba, 2003; Bawah and Binka, 2005; Novignan et al., 2012; Babalola et al., 2013; Sede and Ohemeng, 2015; Mosunmola, 2016). Malaria hits Africa the hardest. Reports of the African Development Bank (2018) posits that more than 80 percent of all malaria cases around the world each year occur in Africa, and the continent suffers more than 90 percent of the fatalities caused by the disease. WHO (2019) report shows that, as at 2018-2019, about 6 countries accounted for more than half of all the malaria cases globally with Nigeria leading (accounting for 25 percent). Others include the Democratic Republic of Congo (12 percent), Uganda (5 percent), Mozambique, Niger and Cote d'Ivoire (4 percent each). Currently, Nigeria accounts for more than 27 percent of global malaria cases largely because over 76 percent of the population live in high transmission areas (USAID, 2021). Children are the most vulnerable of the deaths caused by malaria and 86 percent are among children under five.

Also, climate change could increase the number of people at risk of malaria in Africa by 170 million by 2030 (African Development Bank [AfDB], 2012). The implication of this is that the agrarian communities which suffer high climate change impact are worse affected. This high burden of malaria disease has a direct economic impact. Malaria causes significant economic losses, and can decrease gross domestic product (GDP) by as much as 1.3 percent in countries like Nigeria with high levels of transmission (AfDB, 2012). Over the long term, these aggregated annual losses have resulted in substantial differences in GDP between countries with and without malaria, particularly in Africa (WHO, 2011). There has been a growing political commitment at both regional and international levels to scale up malaria control especially in Africa. The acceleration of malaria prevention strategies which led to the initiation of programmes such as the Roll Back Malaria Programme (RBMP) facilitating the use of insecticide-treated bed nets have shown positive results leading to a reduction of malaria incidence and mortality among children in Africa. The goal of the RBMP, as concluded at the Abuja summit in 2000, is to half the malaria burden by 2010 through appropriate interventions and increase in government expenditure on health (FMOH, 2000; WHO, 2008; Salaudeen and Jimoh, 2009). Clearly, this laudable goal was not achieved in Nigeria because the citizens, 
especially infants still suffer gravely from mortality due to malaria.To sustain the gains, accelerate progress in meeting the malaria-related sustainable development goals, and improve child health, more investment is needed. It is even more pertinent now since Malaria and the novel COVID-19 disease share similar symptoms which has triggered the reluctance of health care centres in attending to malaria cases with consequent spike in the cost of malaria treatment and heavy economic burden on poor agrarian communities.

Reduction in infant mortality rate thus increasing life expectancy to at least 70 years by 2020 and beyond is one of Nigeria's health policy targets (Sede and Ohemeng, 2015; Julien, 2009; Jie, Zhang and Lee, 2001; Courtney, Diamond, Gruber and Jousten, 2002) and main target of many global health and economic projects (Malaria Consortium, 2018). Investing in the social sectors like health, education, sanitation, environmental management and social safety nets is expected to impact on life mortality rate (Babalola, Osuntade, Kio and Agbede, 2019; Kabir, 2008). Not much success has been achieved via these policies and malaria still remains a major cause of death especially among infants in rural communities of Nigeria (Oladepo et al., 2019; USAID, 2021). In Nigeria, as in other developing countries, variations in morbidity and mortality have been associated with a wide variety of measures among which is health care expenditure (Sede \& Ohemeng, 2015).

WHO report showed that between 2000 and 2016, malaria incidence rates (new malaria cases) fell by $37 \%$ globally, and by $42 \%$ in Africa. During this same period, malaria mortality rates fell by $60 \%$ globally and by $66 \%$ in the African Region. This improvement, even though unsteady and not satisfactory, has been adduced to the progress made by the Roll Back Malaria (RBM) policy. The combined use of insecticide treated nets (ITN), rapid diagnostic tests and Artemisinin-based therapy for control of malaria in endemic regions like Nigeria was projected to be funded within the framework of the RBM policy (RBM Partnership, 2020; Babalola et $a l ., 2013)$. The ITN, in particular, has been promising in controlling malaria scourge especially among infants. Unfortunately, despite the huge proposed budget on ITN (USAID, 2021), WHO (2020) reported that ITN coverage has been on a standstill since 2016. Infants in rural communities in particular do not have access to ITNs. This study examined the influence of government expenditure on health (proxy for health policy) and infant mortality and further focused on the trend of expenditure on malaria vis-à-vis reported malaria cases in order to appraise the influence of the RBM policy in Nigeria.

\section{REVIEW OF STUDIES ON THE ECONOMIC BURDEN OF MALARIA, HEALTH EXPENDITURE AND THE ROLLBACK MALARIA POLICY}

The report of the Corporate Alliance on Malaria in Africa (CAMA, 2021) indicated that malaria has a significant impact on business growth in Nigeria, with an estimated annual GDP loss of 1.1 billion dollars due to malaria-related absenteeism and treatment costs. Previous observations of Babalola et al. (2019); Adesoye and Babalola (2017); Arrese (2001) agrees with the World Bank (2000) report that there exists causality between malaria and economic growth. These studies concluded that severe malaria attacks lead to poor health outcomes which in turn lead to a low gross national income and poor economic growth. While assessing the case in African countries, Soyibo, Olaniyan \& Ayorinde, 2005) concluded that human capital is important in fostering economic development. The burden of malaria is estimated to cost Africa $\$ 12$ billion annually (Gallup \& Sachs, 2001) due to treatment (which is largely out- 
of-pocket funded), absenteeism and days lost in education, decreased productivity due to brain damage from cerebral malaria, and loss of investment and tourism. These reports were also consistent with the report of Alaba and Alaba (2003; 2009). Their study reported that the quality and quantity of human capital in African countries, including Nigeria, have been continually affected by low health status and that malaria is the most prevalent of all major tropical diseases in the country. Economic growth, in a nation with a high population like Nigeria, is promoted more by investment in human capital than in physical capital which is largely limited in supply. This is why it is central to the achievement of the Sustainable Development Goals. Sequel to this, Harold and Delworth (2019) added that returns from human capital investment are realized as a flow of labour services through time. However, because adults seldom die of malaria in areas of stable transmission, Okorosobo et al. (2011) argued that the loss associated with human capital investment and loss of productive life is negligible. The mortality rate is however high among children especially below the age of 5 years. Beyond the productive time lost by the caregivers of the sick infant when infected by malaria, the death of a child constitutes an economic burden by reducing the potential future population and labour force.

Yaub, Ojapinwa and Yussuff (2010) observed that a key element of public policy is the promotion of good health in order to attain broad based economic growth. Based on this paradigm, many countries devote huge budgetary allocation to health, but in most developing countries especially, this huge health expenditure failed to translate into better health status. Akinpelu, Amamgbo, Olojede and Oyekale (2011) assessed expenditure on malaria treatment in rural Nigeria and discovered that as much as 13 percent of rural household's out-of-pocket expenditure per month goes to malaria treatment alone. Sede (2017), while assessing expenditure on malaria in Nigeria, observed that there are direct and indirect costs of malaria. The direct costs of malaria include a combination of personal out-of-pocket expenditures, public government expenditures and external finances (like donations) on both prevention and treatment of the disease. Out-of-pocket expenditures include spending on Insecticide Treated Nets (ITNs), doctors' fees, anti-malarial drugs, transport to health facilities, and support for the sick family member and sometimes an accompanying family member during hospital admissions. Public expenditures include spending by the government on maintaining health facilities and health care infrastructure, wages and salaries of doctors and other medical personnel, provision of public healthcare for preventing disease, education and research and so on. He further stressed that in some countries with a huge malaria burden like Nigeria, the disease may account for as much as 40 percent of public health expenditure, 30 percent to 50 percent of inpatient admissions, and up to $50 \%$ outpatient visits.

Ernest (2011) analyzed the dynamic direct and indirect effects of government policy on health and its relation to the cyclical economic growth in the long run. Using an integrated sequential dynamic computable general equilibrium (CGE) model to examine the potential impact of increase in government expenditure on health in Nigeria, the result showed that the reallocation of government expenditure to the health sector is significant in explaining economic growth in Nigeria. He thus recommended that in order to achieve a steady economic growth, investment in health services should also receive great attention in the public investment portfolio. In determining the relationship between deaths from malaria and public health and non-health expenditure in Nigeria, Bello (2005) adopted the Filmer and Pritcher model and the gross output transfer models on data from 1975-2001. The study revealed that there is a negative relationship between deaths from malaria, public health expenditure, per capita income, and non-public health expenditure, but a positive relationship between deaths from 
malaria and political instability. The study further showed that between 1975 and 2001, an average of $5.86 \%$ of the GDP was lost to malaria deaths annually. The author recommended an increase in government expenditure on malaria control. The works of Babalola et al. (2013) and Nwanosike Ikpeze and Ugbor (2015) revealed that increase in expenditure on malaria control is expected to be motivated by the RBMP starting from the year 2000. Actually, as reported by Sede (2017), the decision to increase expenditure on health by 15 percent was reached by the African Union countries in 2001 so as to further support the objective of the RBMP and to facilitate the health related Millennium Development Goal (MDG). However, it does not appear that this commitment has been adequately honored.

\section{Determinants of Infant Mortality}

Bichaka and Gutema (2005) examined the determinants of health status (as measured by reduction in mortality rate) in Africa based on the Grossman (1972) theoretical model which considers the economic (the ratio of health expenditure to GDP and the per capita food availability index), social (illiteracy rate and alcohol consumption) and environmental factors (urbanization rate and carbon monoxide emission per capita index). The study showed that health policy, focusing on the provision of health services, can improve the health status and reduce mortality rate. The work of Wilkinson (1992) established that absolute level of income measured by per capita GDP seems to impact significantly on mortality reduction. Ernest (2011) also found a significant positive relationship between per capita GNP and mortality reduction, which is transmitted through public expenditure on health. Malaria is the leading cause of Infant mortality in Africa generally (WHO, 2019; Babalola et al., 2019). This paper assessed the nexus between malaria health policy (proxied by expenditure on malaria), and infant mortality rate in Nigeria.

\section{METHODOLOGY}

The general consensus in related previous studies (most of which have been hitherto reviewed) is that mortality is a function of environmental factors (such as wealth, education, infrastructure and safety regulations), lifestyle factors (such as nutrition and tobacco or alcohol consumption) and government healthcare policy (expenditure on healthcare). The model for this study is constructed based on the a priori expectation that investment in health policy will more likely impact infant mortality rate significantly. However, environmental factors are incorporated in the empirical model as control variables. Adopting this framework to this study, the empirical model becomes

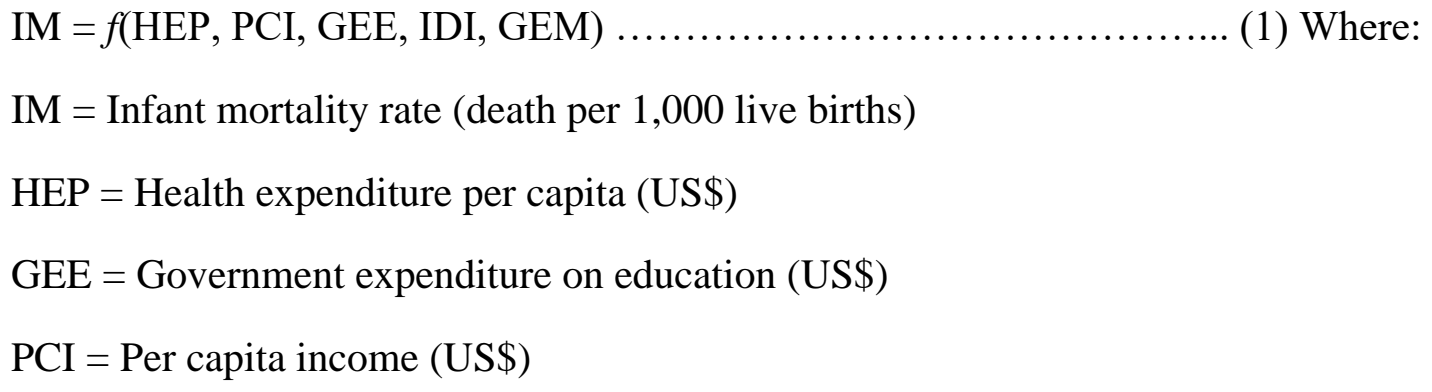


African Journal of Economics and Sustainable Development

ISSN: $2689-5080$

Volume 4, Issue 3, 2021 (pp. 85-97)

www.abjournals.org

IDI $=$ infrastructure development index

GEM = Government Expenditure on malaria (US\$)

The variables (which have already been modified to remove ambiguity in unit) are fit into a regression model to obtain:

$\operatorname{lnIM}=\alpha_{0}+\alpha_{1} \ln \mathrm{HEP}+\alpha_{2} \operatorname{lnGEE}+\alpha_{3} \mathrm{PCI}+\alpha_{4} \mathrm{IDI}+\alpha_{5} \ln \mathrm{GEM}+\mathrm{e}_{\mathrm{i}}$

\section{Data Sources and Measurement}

This study used data from 1990 to 2019 obtained from the World Bank and WHO and African Development Bank database. Government expenditure was measured in US dollars while infant mortality was measured as death per 1000 live births.

\section{RESULT AND DISCUSSION}

\section{Preliminary Analysis - Descriptive and diagnostic tests}

From Table 1, which present the descriptive statistics of the measured variables, the mean and median of all the variables lies between the minimum and maximum values which indicated adequate and symmetrical distribution. A fat-tailed or thick-tailed distribution has a value for kurtosis that exceeds 3 . That is, excess kurtosis is positive. This is called leptokurtosis. Aside for GEM that has kurtosis values $>3$, all the other variables are mesokurtotic that is the value of kurtosis is less than 3, meaning they are normally distributed. Therefore they are continuous in nature and can be differenced more than once. The result of the Jarque-Bera for all the variables shows that none of the residuals is statistically significant. This is desirable because it shows that there is no serial correlation or heteroskedasticity problem and the model is normally distributed.

Table 1: descriptive statistics of variables

\begin{tabular}{lcccccc}
\hline & IM & HEP & PCI & GEE & IDI & GEM \\
\hline Mean & 99.63929 & 60.46508 & 1231.821 & $2.86 E+09$ & 35.88357 & 43.08214 \\
\hline Median & 101.3500 & 54.10699 & 599.0011 & $3.87 \mathrm{E}+08$ & 36.25847 & 28.95000 \\
\hline Maximum & 126.2000 & 114.9669 & 3126.465 & $1.21 \mathrm{E}+10$ & 43.50973 & 143.0000 \\
\hline Minimum & 66.90000 & 16.25760 & 153.0823 & $1.37 \mathrm{E}+08$ & 23.76678 & 18.00000 \\
\hline Std. Dev. & 21.30163 & 32.59342 & 1040.166 & $4.32 \mathrm{E}+09$ & 5.871529 & 33.66808 \\
\hline Skewness & -0.169402 & 0.291810 & 0.466241 & 1.152002 & -0.495210 & 1.634633 \\
\hline Kurtosis & 1.547863 & 1.781800 & 1.598198 & 2.550630 & 2.340874 & 4.657029 \\
\hline & & & & & & \\
\hline Jarque-Bera & 2.594071 & 2.128729 & 3.306999 & 6.428766 & 1.651274 & 15.67282 \\
\hline Probability & 0.273341 & 0.344947 & 0.191379 & 0.040180 & 0.437956 & 0.000395 \\
\hline
\end{tabular}


African Journal of Economics and Sustainable Development

ISSN: 2689-5080

Volume 4, Issue 3, 2021 (pp. 85-97)

www.abjournals.org

\begin{tabular}{lcccccc}
\hline Sum & 2789.900 & 1693.022 & 34490.98 & $8.01 \mathrm{E}+10$ & 1004.740 & 1206.300 \\
\hline Sum Sq. Dev. & 12251.51 & 28682.94 & 29212506 & $5.03 \mathrm{E}+20$ & 930.8210 & 30605.56 \\
\hline Observations & 29 & 29 & 29 & 29 & 29 & 29 \\
\hline
\end{tabular}

Result in Table 2 shows that there was a relatively consistent decline in infant mortality rate over the years under review. Mortality rate declined from 126 per 1,000 live births in 1990 to approximately 61 per 1,000 live births in 2019. A gradual decline in infant mortality rate (though not at constant rate) was experienced between 1990 and 2013.

Table 2: Trend statistics of infant mortality rate and Nigerian government expenditure on malaria (1990 - 2019)

\begin{tabular}{|c|c|c|}
\hline Year & Infant Mortality rate (per 1,000 live birth) & Expenditure on malaria (Million US\$) \\
\hline 1990 & 125.88 & 18 \\
\hline 1991 & 125.87 & 19.5 \\
\hline 1992 & 125.87 & 20 \\
\hline 1993 & 125.86 & 20 \\
\hline 1994 & 124.39 & 19.9 \\
\hline 1995 & 122.92 & 20 \\
\hline 1996 & 121.45 & 20 \\
\hline 1997 & 119.98 & 21 \\
\hline 1998 & 118.50 & 20 \\
\hline 1999 & 115.59 & 20 \\
\hline 2000 & 112.68 & 20 \\
\hline 2001 & 109.78 & 20.2 \\
\hline 2002 & 106.87 & 40 \\
\hline 2003 & 103.96 & 35 \\
\hline 2004 & 101.03 & 30.9 \\
\hline 2005 & 98.11 & 33.8 \\
\hline 2006 & 95.18 & 110 \\
\hline 2007 & 92.26 & 110 \\
\hline 2008 & 89.33 & 143 \\
\hline 2009 & 86.46 & 102 \\
\hline 2010 & 83.59 & 65 \\
\hline 2011 & 80.72 & 50 \\
\hline 2012 & 77.84 & 40 \\
\hline 2013 & 74.97 & 43 \\
\hline 2014 & 72.41 & 27 \\
\hline 2015 & 69.84 & 26 \\
\hline 2016 & 67.27 & 56 \\
\hline 2017 & 64.71 & 56 \\
\hline 2018 & 62.14 & 64 (estimated) \\
\hline 2019 & 60.66 & 64 (estimated) \\
\hline
\end{tabular}

Source: Computed from WHO, World bank and Macrotrends databases (2020) 
The rate of decline stabilized at $0.07 \%$ between 2000 and 2003, which tallied with the inception of the RBM programme, and increased in subsequent years from $0.09 \%$ in 2004 to 0.13 in 2013. However, it is expected that there will be a sharper decline in the years with sharp increase in government expenditure (2006 to 2008) as compared to the years with less fluctuation in government expenditure on malaria (2000 and 2005). The sudden sharp fall in funding received between 2008 and 2009, and between 2013 and 2014 is suspected to be responsible for the reduction or poor rate of decline in mortality in these periods.

\section{Unit root test (Augmented Dickey-Fuller Test, ADF) and Engle-Granger co-integration test}

Most time series are non-stationary in nature, meaning they have unit root and cannot be plugged into regression headlong. Therefore, before commencing analysis it is prudent to carry out a stationarity test. Due to the non- stationary tendencies of most time series, we commenced the analysis for this study by testing the unit roots of all the variables included in the model to determine their stationary levels. The results are presented in Table 3.

\section{Table 3: Output of the Augmented Dickey-Fuller (ADF) Test}

\begin{tabular}{lll}
\hline Variable & t-value & Order of integration \\
\hline IM & $-3.860^{*}$ & $\mathrm{I}(1)$ \\
\hline HEP & $-5.073^{*}$ & $\mathrm{I}(1)$ \\
\hline PCI & $-3.668^{*}$ & $\mathrm{I}(1)$ \\
\hline GEE & $-4.714^{* *}$ & $\mathrm{I}(1)$ \\
\hline IDI & $-4.405^{*}$ & $\mathrm{I}(1)$ \\
\hline GEM & $-4.696^{*}$ & $\mathrm{I}(1)$ \\
\hline
\end{tabular}

$*(* *)$ Significant at $0.05(0.01)$

All the variables have unit root at level meaning non-stationary but they all become stationary at first difference I(1). The regression of a non-stationary time series on another non-stationary time series may cause a spurious regression.

The Engle-Granger co-integration technique was further applied to examine the extent of relationship between the dependent and each of the explanatory variables. The Engle -Granger two-step method is suitable, given that it is a single equation model and integrated of order one.

Table 4: Engle-Granger co-integration test

\begin{tabular}{ll}
\hline ADF test statistics & t-statistics \\
\hline Critical values (Engle-Granger) ${ }^{\dagger}:$ & $-4.838^{*}$ \\
\hline $1 \%$ level & -3.724 \\
\hline $5 \%$ level & -2.986 \\
\hline $10 \%$ level & -2.633 \\
\hline
\end{tabular}

${ }^{\dagger}$ MacKinnon (2010); * Significant at 0.05 
We followed two steps: estimation of the co-integration model and test for the stationarity of the residuals. Result in Table 4 shows that the residuals are stationary at 5\% significance level. The implication of this is that there is the existence of a long run equilibrium relationship between the variables in the model thus they can co-integrate in the long run without change in their behaviours. This qualifies the model as a long run model. The confirmation of a longrun relationship between the variables suggests the adoption of the Error Correction Model (ECM) to remedy the disequilibrium that previously existed. The result of the ECM is presented in Table 5.

The coefficient of determination $\mathrm{R}^{2}$ is 0.52 which indicates that 52 percent of the variation in the independent variable is explained by the joint variation in the explanatory variables. The significance of the F-statistics showed that the overall model is statistically significant at $5 \%$. Furthermore, the fact that the value of the $\mathrm{R}^{2}$ is less than the value of the Durbin-Watson statistics shows that the model is not spurious.

Table 5: Output of the ECM model

\begin{tabular}{lrrr}
\hline \multicolumn{1}{c}{ Variable } & Coefficient & t-Statistic & \multicolumn{1}{c}{ Prob. } \\
\hline \multicolumn{1}{c}{ C } & -0.028987 & -8.369706 & 0.0000 \\
\hline \multicolumn{1}{c}{ D(HEP) } & -0.003141 & -0.420577 & 0.6790 \\
\hline D(PCI) & -0.000980 & -0.095831 & 0.9247 \\
\hline D(GEE) & -0.002456 & -0.508193 & 0.6175 \\
\hline D(IDI) & -0.006124 & -1.941540 & 0.0480 \\
\hline \multicolumn{1}{c}{ D(GEM) } & -0.002616 & -0.381958 & 0.0170 \\
U(-1) & -0.336700 & -0.477480 & 0.6388 \\
\hline R-squared & 0.521225 & Mean dependent var & -0.025136 \\
\hline $\begin{array}{l}\text { Adjusted R- } \\
\text { squared }\end{array}$ & 0.38367 & S.D. dependent var & 0.011425 \\
\hline S.E. of regression & 0.011642 & Akaike info criterion & -5.836894 \\
\hline $\begin{array}{l}\text { Sum squared } \\
\text { resid }\end{array}$ & 0.002440 & Schwarz criterion & -5.495609 \\
\hline Log likelihood & & & -5.742236 \\
\hline F-statistic & 79.96118 & Hannan-Quinn criter. & \\
\hline Prob(F-statistic) & $0.852204 *$ & Durbin-Watson stat & 0.809871 \\
\hline
\end{tabular}

$*(* *)$ Significant at $0.05(0.01)$

The Error Correction Term ECT (denoted by U(-1) in the Table 5 is significant with a negative sign which lends validity to the existence of long run equilibrium relationship between the dependent and independent variables. Also, the ECT (-1) indicates the speed of adjustment of the model from the short run to the long run. Thus, disequilibrium in the system is corrected by the ECT at a speed of approximately $34 \%$ annually.

The analysis of the estimated coefficients in the model showed that only infrastructure development index (IDI) and government expenditure on malaria (GEM) significantly 
influenced (reduce) infant mortality rate. The coefficients of GEM and IDI are significant with negative signs at $5 \%$.

\section{DISCUSSION OF FINDINGS}

The descriptive result of the trend analysis of infant mortality rate and Nigerian government expenditure on malaria showed a gradual decline (though not constant) in the rate of infant mortality in Nigeria between 2009 and 2019. However, slight stability was achieved at inception of the roll back malaria programme. Further analysis showed a suspected nexus between government expenditure on malaria and infant mortality rate. This result is consistent with the findings of Mosunmola et al. (2016). The early 2000s enjoyed apparent higher healthcare financing with respect to malaria most probably because of the high awareness creation for the roll back malaria policy and the expenditure made in ensuring infants and pregnant women have access to treated mosquito nets especially in the rural agrarian communities. The periods with low or non-response of the mortality rate to the surge in government expenditure may be due to influence of other mortality causing variables besides malaria or governance (in implementation and corruption and these are usually difficult to measure). The impact of corruption in government on health policy implementation has been noted by Yaqub et al. (2010).

Further results confirmed that increase in government expenditure on malaria (proxy for government policy on malaria) and infrastructural development reduced infant mortality rate significantly. This implies that deliberate policies targeting sustainable provision and development of infrastructure and specifically financing control of malaria will reduce the rate of infant mortality in Nigeria. This result is both consistent with and affirms the previous observations of Sede and Ohemeng (2015); Adesoye and Babalola (2017) and Sede (2017).

\section{CONCLUSION AND RECOMMENDATION}

Malaria is significantly endemic in agrarian economies like Nigeria. Besides the economic and psychological burden that the scourge of malaria can cause, the loss of infants due to malaria can reduce life expectancy and economic development. There has been scanty information answering the question of how the government is responsive to financing the fight against infant killer diseases such as malaria in Nigeria. This study examined the relationship between government expenditure on malaria, per capita income, infrastructure development index, government expenditure on education and health (control variables) and infant mortality rate in Nigeria using data from 1990 to 2019. Based on the findings, the following have been recommended for policy action:

1. Improvement in government funding of malaria control strategies in the country should be prioritized. The political will and sufficient administrative apparatus to drive the infant health related goals as highlighted in the rollback malaria policy, SDG and so on, in Nigeria is pertinent. 
2. Government should put more effort into developing infrastructure, especially facilitating healthcare delivery in the rural agrarian communities where malaria attack is prevalent.

\section{REFERENCES}

Abu, I. N., Madu, I. A., \& Ajaero, C. K. (2015). The Prevalence and Determinants of UnderFive Mortality in Benue State, Nigeria. SAGE Open J, 2015, 1-11

Adeokun, L. (1985). Problems of Health Intervention Programmes: the Case of Nigeria" in Health Policy, Social Policy and Mortality Prospects, Vallin J and Lopez A D (eds), IUSSP, Liege, 180-192.

Adesoye, B. A., \& Babalola, D. A. (2017). Health Policy and Mortality Rate Expectancy in Nigeria. Canadian Journal of Pure and Applied Sciences 11(3), 4349-4354

African Development Bank [AfDB] (2017). West African regional overview. Available at www.afdb.org/en/countries/west-africa/west-africa-overview

African Development Bank [AfDB] (2018). African Development Bank socio-economic database, 1960-2019. Available at http://dataportal.opendataforafrica.org/bbkawjf/afdbsocio-economic-database-1960-2019

Ahonsi, B (1992). Developmental Implications of Early Mortality Factors in Nigeria Journal of Social Development in Africa 7 (1), 67-85

Alaba, O. A., \& Alaba, O. B. (2003). Malaria in children: implications for the productivity of female caregivers in Nigeria. Proceedings of Annual Conference of the Nigerian Economic Society (NES):395-413.

Babalola, D. A., Olarewaju, M., Omeonu, P. E., Adefelu, A. O., \& Okeowo, R. (2013). Assessing The Adoption of Roll Back Malaria Programme (RBMP) among Women Farmers in Ikorodu Local Government Area of Lagos State. Canadian Journal of Pure and Applied Science, 7(2), 2375-2379

Babalola, D.A., Osuntade, B.O., Kio, J.O., \& Agbede, C.O. (2019). Economic burden of malaria and productivity of farmers in Nigeria: Evidence from Ogun State. The Journal of Applied Sciences Research, 6(4): 1- 13.

Bawah, A. A., \& Binka, F. N. (2005). How many years of life could be saved if malaria were eliminated from the hyperendemic areas of Northern Ghana. Population Council Working Paper No. 203.

Bello, R. (2005). Reducing the impact of malaria in Nigeria: A public health expenditure conundrum. Nig. J. Econ \& Soc. Studies. 2005; 47, 175-186.

Bichaka, F., \& Gutema, P. (2005). The determinants of health status in Sub-Saharan Africa (SSA). Am Econ, 42(2), 60-72

Corporate Alliance on Malaria in Africa (CAMA) (2021). Mobilizing Nigeria's private sector for Malaria control \& elimination CAMA two-year commitment report. Available at: http://www.gbchealth.org/wp-content/uploads/2017/05/Nigeria Report_print_v3.pdf, assessed May 2021

Courtney, C., Diamond, P., Gruber, J., \& Jousten, A. (2002). Delays in claiming social security benefits. J Public Econ, 84, 357-385.

Cutler, David, Angus Deaton \& Adriana Lleras-Muney. (2006). The determinants of mortality. Journal of Economic Perspectives 20(3), 97-120. 
Ernest, S.O.O. (2011). Government expenditure on health, economic growth and long waves in a CGE micro-simulation analysis: The case of Nigeria. European Journal of Economics, Finance and Administrative Sciences-Issue, 31, 99-113.

Gallup, J. L., Sachs, J. D., (2001). The economic burden of malaria. AJTMH 64 (Suppl 1-2), 85-96.

Gradstein, M., \& Kaganovich, M. (2004). Aging population and education finance. J Public Econ 88, 2469-2485.

Grant, P. (1988). The State of the World's Children -1988, Oxford University Press for UNICEF, Oxford.

Grossman, M. M. (1972). On the Concept of Health Capital and the Demand for Health. Journal of Political Economy, 80:223-255

Harold, H., \& Delworth, B. (2019). Health as human capital: Theory and Implications. A new management paradigm. Available at www.hcmsgroup.com

Jie, Z., Zhang, J., \& Lee, R. (2001). Mortality decline and long run economic growth. $J$ Public Econ 80, 485-507.

Julien, B. (2009). Life expectancy is essentially affected by wealth and education. Revising the retirement age in social security is dangerous. Older Women's Economic Security Task Force. Available at www.socialsecuritymatters.org.

Kabir, M. (2008). Determinants of life expectancy in developing countries. J Dev Area, 41, $185-204$.

Malaria Consortium. (2018). Project brief: Reducing the malaria burden in Nigeria. Available at https://www.malariaconsortium.org/media-downloads

Mosunmola, G., Moses, U., \& Gabriel, S, U. (2016). Can the government deliver quality rural healthcare? Empirics on malaria prevention and control in Nigeria. Asian Journal of Economic Modelling, , 4(2), 70-81

Novignon, J., Olakojo, S. A., Nonvignon, J. (2012). The effects of public and private health care expenditure on health status in sub-Saharan Africa: new evidence from panel data analysis. Health Econ Rev, 22(2), 22.

Okorosobo, T., Okorosobo, F., Mwabu, G., Orem Juliet Nabyonga \& Kirigia Joses Muthuri (2011). Economic Burden of Malaria in six Countries of Africa. European Journal of Business and Management 3(6). Available at https://www.iiste.org

Oladepo, O., Oyeyemi, A.S., Titiloye, M.A., Adeyemi, A. S., Burmett, S.M., Aoera, I., Oladunni, O \& Alliu, M. (2019). Malaria testing and treatment knowledge among selected rural patent and proprietary medicine vendors (PPMV) in Nigeria. Malaria Journal. 18: 103.

Ransome-Kuti, I. (1986). That Our Children Will Not Die: Part II, Inaugural Lecture Series, Lagos University Press, Lagos.

RBM Partnership (2020). Roll Back Malaria (RBM) Partnership to end malaria: COVID-19 and Malaria. Accessed May 2020 https://endmalaria.org/covid19andmalaria

Salaudeen, G. A., \& Jimoh, R. O. (2009). Awareness and use of Insecticide Treated Nets among women attending antenatal clinics in a Northern state of Nigeria. Journal of Pakistan Medical Association (JPMA). 59, 354.

Sede, I. P. (2017). Government Health Expenditure and Malaria in Nigeria Journal of Social and Management Sciences 3 (1), June 2017

Sede, I., \& Nosakhare, I. (2018). Government health expenditure and malaria in Nigeria. Yobe J. Econ. 5, 19-34

Sede, P., \& Ohemeng, W. (2015). Socio-economic determinants of life expectancy in Nigeria (1980 - 2011). Health Economics Review 52-11 
Soyibo, A ., Olaniyan, O., \& Ayorinde. F. (2005). Economic cost of disease in Sub-Saharan Africa: A situational review. Nigerian J. Econ. \& Soc. Studies. 2005; 47, 1-18.

USAID (2021). USAID President's Malaria Initiative FY 2021 Nigeria Malaria Operational Plan Available at: https://www.pmi.gov/where-we-work/nigeria/

Wilkinson, R. G. (1992). Income distribution and life expectancy. Br Med J, 304, 165-168.

World Bank. (2016). Life expectancy statistics: World Bank database. Available online at www.dataworldbank.org

World Health Organization (2011). WHO Malaria Fact Sheet number 94. December 2011. Available at www.who./malaria

World Health Organization (2015). Facts sheet world malaria report. Available online at http://www.who.int/malaria/media/world-malaria-report-2015/en/

World Health Organization (2019). The world malaria report at a glance. Accessed May 2020 https://www.who.int/news-room/feature-stories/detail/world-malaria-report-2019

World Health Organization (2020). Facts Sheet on Malaria. Accessed August 2020 https://www.who.int/news-room/fact-sheets/detail/malaria

Yaqub, J.O., Ojapinwa, T.V., \& Yussuff, R. O. (2010). Public Health Expenditure and Health Outcome in Nigeria: The Impact of Governance. European Scientific Journal 8 (13), $189-202$ 